\title{
MicroRNAs in diffuse large B-cell lymphoma (Review)
}

\author{
HUIYUN NI ${ }^{1}$, RONG TONG ${ }^{1}$, LINQING ZOU ${ }^{2}$, GUOQI SONG $^{1}$ and WILLIAM C. $\mathrm{CHO}^{3}$ \\ ${ }^{1}$ Department of Hematology, Affiliated Hospital of Nantong University; \\ ${ }^{2}$ Department of Anatomy, Nantong University College of Medicine, Nantong, Jiangsu 226001; \\ ${ }^{3}$ Department of Clinical Oncology, Queen Elizabeth Hospital, Hong Kong 999077, P.R. China
}

Received December 3, 2014; Accepted December 3, 2015

DOI: $10.3892 / \mathrm{ol} .2015 .4064$

\begin{abstract}
The aberrant expression of microRNAs (miRs) has a significant impact on the biological characteristics of lymphocytes, and is important in the pathogenesis of diffuse large B-cell lymphoma (DLBCL). It has been demonstrated, using $\mathrm{miR}$ profiling and detecting distinct miR signatures, that certain miRs may accurately distinguish different subtypes and prognostic classifications of DLBCL, as well as distinguish DLBCL from other more indolent lymphomas, including follicular lymphoma. miRs are excellent biomarkers for cancer diagnosis and prognosis. In DLBCL, specific miR expression profiles in the tissues of patients are associated with prognosis and clinical outcome. Over the past decade, there has been substantial investigation concerning the pathogenetic, diagnostic and prognostic roles of miRs in DLBCL. The aim of the present review is to describe the aberrant expression of miRs in DLBCL, and the functions, potential clinical use and possible therapeutic targets of miRs in this disease.
\end{abstract}

\section{Content}

1. Introduction

2. Aberrant expression of miRs in DLBCL

3. Functions and targets of dysregulated miRs in DLBCL

4. miRs in the diagnosis, subtype classification and prognosis of DLBCL

5. miRs as potential therapeutic targets in DLBCL

6. Conclusion

Correspondence to: Dr Guoqi Song, Department of Hematology, Affiliated Hospital of Nantong University, 20 Xisi Road, Nantong, Jiangsu 226001, P.R. China

E-mail: songguoqi22@sina.com

Dr William C. Cho, Department of Clinical Oncology, Queen Elizabeth Hospital, Block R, 30 Gascoigne Road, Hong Kong 999077, P.R. China

E-mail: williamcscho@gmail.com

Key words: diffuse large B-cell lymphoma, microRNAs, regulator gene, diagnosis, prognosis, therapeutic targets

\section{Introduction}

Diffuse large B-cell lymphoma (DLBCL) is the most common subtype of non-Hodgkin's lymphoma (NHL), and accounts for approximately one third of patients with NHL. DLBCL is an aggressive malignancy and, due to its heterogeneity in genetic abnormalities, clinical features, response to treatment and prognosis, patients with DLBCL have highly variable outcomes (1). Despite the improvement in DLBCL treatment, which includes the combination of rituximab with cyclophosphamide, adriamycin, vincristine and prednisone (R-CHOP), $25-33 \%$ of patients succumb to DLBCL (2). Therefore, studies that investigate methods to provide earlier diagnosis and discrimination between subtypes of DLBCL and additional therapies and individual treatment are required.

MicroRNAs (miRs) are a family of small regulatory RNA molecules. These non-coding RNAs are 18-24 nucleotides in length and regulate gene expression by pairing with the 3'-untranslated region of a target messenger (m) RNA, which leads to the inhibition of protein translation and/or induction of mRNA degradation (3). miRs modulate critical cell processes, including cell growth, development and differentiation (3). Previously, it has been demonstrated that miRs are important in tumor development, and that they may act as tumor suppressor genes or oncogenes (4). Altered expression levels of miRs have been associated with specific cell-differentiation stages, cancer types, tumor stages and patient response to treatments, and the expression patterns of specific miRs are powerful diagnostic and prognostic tools $(5,6)$. Previous studies have demonstrated that miRs in the serum or plasma are extremely stable and may be detected at low quantities, even at picogram concentrations $(5,7)$. Consequently, miRs are considered to be efficient, non-invasive markers for use in clinical diagnosis, differentiation between pathological types and clinical stages, selection of chemotherapy and prediction of therapeutic effect. Furthermore, one therapeutic target, MRX34, which is a mimic of miR-34a, has entered phase I clinical trials for the treatment of patients with primary liver cancer (8). This may provide an alternative therapeutic target for patients with other types of cancer, including DLBCL. The present review focuses on the results of recent studies and briefly describes the aberrant expression of miRs in DLBCL, and the functions, potential clinical use and possible therapeutic targets of miRs in this disease. 


\section{Aberrant expression of miRs in DLBCL}

Numerous studies have indicated that the aberrant expression of miRs is associated with various types of human cancer, including lymphomas (9-12). Since the development of genomics, miRs have become a region of increased interest within cancer research. Therefore, numerous methods have been developed for the detection of miRs, including reverse transcription-quantitative polymerase chain reaction (RT-qPCR), which, due to high sensitivity and specificity, is the most useful and commonly used method (13). RT-qPCR has led to the detection of numerous miRs that are dysregulated in DLBCL compared with normal controls. Fang et al (14) reported that five miRs (miR-15a, miR-16-1, miR-21, miR-29c and miR-155) were significantly elevated in the serum of DLBCL patients compared with normal controls, whilst serum miR-34a was downregulated in these patients compared with controls. Roehle et al (15) reported that there were $15 \mathrm{miRs}$ differentially expressed between DLBCL and normal tissues; four miRs (miR-210, miR-155, miR-106a and miR-17-5p) had a significantly increased expression, and $11 \mathrm{miRs}$ (miR-150, miR-145, miR-328, miR-139, miR-99a, miR-10a, miR-95, miR-149, miR-320, miR-151 and miR-let7e) had a significantly decreased expression in DLBCL tissues compared with normal tissues. Among these $15 \mathrm{miRs}$, the expression of miR-210 was the most increased and miR-150 was the most decreased (15). In addition, Roehle et al (15) demonstrated that the expression profiles of various miRs had the ability to distinguish between different lymphomas, including DLBCL and follicular lymphoma (FL), and the DLBCL germinal center B cell (GCB) subgroup and non-GCB subgroups. This finding was also revealed by Lawrie et al (16), who reported that miR expression profiles varied between activated $B$ cell (ABC) and GCB subtypes of DLBCL; the ABC-type immunophenotype expressed significantly higher levels of miR-155, miR-221 and miR-21 compared with GCB-like immunophenotypes.

\section{Functions and targets of dysregulated miRs in DLBCL}

Previous studies have confirmed that miRs are involved in the pathogenesis of DLBCL $(17,18)$. In 2009, Li et al (19) used a miR chip method to analyze the expression of pathological tissues from 59 patients with DLBCL and 26 types of existing DLBCL cell lines. The authors proposed that $63 \mathrm{miRs}$ are involved in the development and progression of DLBCL. Understanding the biological function of these miRs may aid in elucidating the pathogenesis of DLBCL.

miR-155 has carcinogenic potential and is frequently upregulated in B-cell lymphoproliferative disorders (3). Studies have demonstrated that, compared with normal controls, miR-155 is significantly upregulated in DLBCL, and that its expression is significantly increased in patients with non-GCB-type versus GCB-type DLBCL (20). The central role of miR-155 in the pathogenesis and aggressiveness of DLBCL has been clearly defined (9): miR-155 directly downregulates V-Myc avian myelocytomatosis viral oncogene homolog (MYC) antagonists, including mitotic arrest deficient-like 1, MYC-associated factor X (MAX)-interacting protein 1, and MAX network transcriptional repressor. miR-155 may act in combination with MYC or MYC-associated pathways, which leads to the transformation of B cells (21). miR-155 is essential for the growth of DLBCL cells in vitro, their ability to effectively move from G1 to $\mathrm{S}$ phase of the cell cycle, and inhibition of apoptosis in these cells (22). Other studies have demonstrated that miR-155 may target mRNAs that function in key cell signal transduction pathways (23-25) and cell cycle regulatory pathways (26). In addition, a study reported that the oncogenic activity of miR-155 is correlated with B-cell integration cluster (BIC) RNA (27), which has been associated with the upregulation of c-MYC. However, Rai et al (28) identified no association between the BIC transcript and mature miR-155 in DLBCL. Subsequently, Rai et al (24) studied the functions and regulator target genes of miR-155, and confirmed that miR-155 directly targets the bone morphogenetic protein (BMP)-responsive transcriptional factor SMAD5. Furthermore, the authors revealed that a non-canonical signaling module, which links transforming growth factor $\beta 1$ (TGF- $\beta 1$ ) signals with SMAD5, is also activated in DLBCL. Therefore, overexpression of miR-155 inhibits the expression of SMAD5 and protects diffuse large B cells from the growth-inhibitory effects of TGF- $\beta 1$ and BMP, which leads to a loss of control of cell proliferation (24). In addition, miR-155 directly downregulates the germinal center-specific human germinal center-associated lymphoma (HGAL) gene, which leads to decreased Ras homolog family member A activation and increased lymphoma cell motility, therefore contributing to the invasion and metastasis of DLBCL (9) and indirectly downregulating B-cell lymphoma (BCL)-6 through the repression of the BCL-6 corepressor histone deacetylase 4 (29). Additionally, miR-155 is a key regulator of the phosphatidylinositol 3-kinase (PI3K)-protein kinase B (AKT) pathway (30). PI3K regulatory subunit 1 (PI3KR1) is a negative regulator of the PI3K-AKT pathway, and has been identified as a direct target of miR-155, which may block the activation of AKT (30). Overexpression of miR-155 downregulates transcription and translation of PIK3R1 and activates the PI3K-AKT signaling pathway, which leads to increased cell proliferation and inhibition of cell apoptosis. In DLBCL cell lines, inhibition of the expression of miR-155 promotes the apoptosis of tumor cells (30). Overall, these studies indicate that miR-155 is an oncomiR in the development of DLBCL.

miR-21 is another miR that has been revealed to be dysregulated in DLBCL and appears to be crucial in the majority of human cancers. A previous study demonstrated that overexpression of miR-21 resulted in pre-B cell lymphoma, illustrating the significant impact of miR-21 in tumor development (31). Therefore, numerous studies have been undertaken to investigate the role of miR-21 in DLBCL and have revealed that miR-21 is associated with tumour growth, invasion and metastasis through targeting multiple tumour and metastasis suppressor genes, including programmed cell death 4 (neoplastic transformation inhibitor), tropomyosin 1- $\alpha$ and phosphatase and tensin homolog (PTEN) (10-12,14,32-35). In addition, Cheng et al (34) verified, using antisense inhibition of human miRs, that miRs are mediators for the regulation of cell growth and apoptosis pathways, and demonstrated that an inhibition of miR-21 leads to a clear increase in the growth of HeLa human cervical adenocarcinoma cells. These results are similar to the results reported by Si et al (32), that miR-21 has an anti-proliferative effect in certain types of 
cancer. However, studies focusing on the physiological and pathophysiological functions of miR-21 require additional investigation. Lawrie et al (36) identified interesting candidate genes that should undergo additional study, including pleomorphic adenoma gene 1, E2F transcription factor 3, Jagged 1, avian sarcoma viral proto-oncogene and signal transducer and activator of transcription 3. A recent study by Li et al (37) identified that the expression levels of miR-21 are negatively correlated with the level of PTEN, which suggests that PTEN is possibly a target of miR-21 in DLBCL. Overall, these results clearly indicate that miR-21 is a key oncogene in certain types of human cancer, including DLBCL.

The miR-17-92 cluster and its homologous clusters, miR-106a-92 and miR-106b-25, are important oncogenes in the development of DLBCL, and may promote tumorigenesis by negatively regulating tumor suppressor genes (38). The miR-17-92 cluster is encoded at the 13q31 locus, a region commonly amplified in lymphoma, and ectopic expression of miR-17-92 greatly accelerates lymphomagenesis in a murine model $(39,40)$. Numerous studies have revealed that the function of miR-17-92 is associated with c-MYC (3,40-43), and a negative feedback loop may exist between miR-17-92 and c-MYC. This is important in the regulation of cell proliferation and apoptosis as it induces the growth of B-cell lymphoma by reducing apoptosis and promoting the proliferation of lymphoma cells (39). In addition to c-MYC, gene amplification at $13 \mathrm{q} 31$ is an additional target for miR-17-92 $(16,42)$. A 13q31 amplification encodes the parental transcript of miR-17-92, c13orf25 $(38,39,44)$. When overexpressed with MYC, c13orf25 has been demonstrated to accelerate tumor development in a murine B-cell lymphoma model (39). There are several other potential targets for miR-17-92, including proapoptotic BCL-2 interacting mediator of cell death, PTEN and E2F transcription factor 1, which is a direct target of MYC and promotes cell cycle progression (3). Thapa et al (45) reported that miR-17, miR-106a and miR-106b regulate the proliferation, apoptosis and invasion of DLBCL cells by repressing the expression of cyclin-dependent kinase inhibitor 1 .

As a tumor suppressor, miR-150 is consistently downregulated in the majority of lymphomas (46). A study has demonstrated that in hematopoietic lineages and B cell subsets of tonsil tissues, the expression level of miR-150 is inversely proportional to the expression of $\mathrm{V}-\mathrm{Myb}$ avian myeloblastosis viral oncogene homolog (c-MYB) (47). In addition, Xiao et al (46) confirmed that mice lacking miR-150 have an increased expression of c-MYB. c-MYB oncogene is a transcription factor and is required for the development of adult hematopoietic stem cell-derived blood cell lineages, and is important in lymphocyte development and maturation $(3,46,48)$. However, the role of miR-150 and c-MYB in DLBCL remains unclear and additional investigation to elucidate the association is required.

Calin et al (49) have reported that miR-15a and miR-16 negatively regulate the antiapoptotic gene BCL-2. Therefore, a deletion or downregulation of these miRs may lead to the overexpression of BCL-2, which may inhibit cell apoptosis, and eventually result in the development of cancer, including leukemia, lymphoma and prostate cancer. miR-15a and miR-16 may be associated with the development of DLBCL, although this remains unclear.
There are numerous other miRs that are dysregulated in DLBCL, including miR-181a, which potentially targets forkhead box protein P1 and O-6-methylguanine-DNA methyltransferase (50). In addition, miR-9 is associated with the downregulation of $\mathrm{B}$ lymphocyte-induced maturation protein-1 expression in DLBCL (51), and miR-199 is associated with tumour progression through targeting inhibitor of nuclear factor $\kappa \mathrm{B}(\mathrm{NF}-\kappa \beta)$ kinase subunit $\beta$ (52), which is an important regulator of the NF- $\kappa \beta$. Dysregulated NF- $\kappa \beta$ has been demonstrated to be associated with survival, proliferation and apoptosis of lymphoma cells (53). A summary of the miRs that have an aberrant expression in DLBCL and their targets are presented in Table I.

\section{4. miRs in the diagnosis, subtype classification and prog- nosis of DLBCL}

Methods for cancer diagnosis are often inconvenient, expensive and invasive, and early-stage cancer is frequently challenging to detect. Therefore, physicians require novel approaches that overcome the disadvantages of current methods. miRs have provided a novel method for diagnosing DLBCL and predicting the treatment response of patients. Numerous studies have demonstrated that various miRNAs are dysregulated in human cancers, and their expression has specificity for particular tissues, neoplasms, and even cell types. miR expression profiles and specific miRs in the tissue of patients have been demonstrated to be associated with prognosis and clinical outcome in patients with DLBCL $(40,50,54-56)$.

Potential biomarkers for diagnosis. A previous study revealed that the expression of miR-21 and miR-210 is increased, and the expression of miR-486-5p is decreased in the plasma of patients with malignant solitary pulmonary nodules (SPNs) compared with plasma from patients with benign SPNs and healthy controls (57). These results suggest that the these miRs are potential plasma biomarkers for the identification of malignant SPNs (57). Therefore, miRs may be useful tools in the diagnosis of malignancies.

DLBCL is a heterogeneous disease, which has various subtypes and outcomes, and numerous previous studies have confirmed that miR expression profiles function as biomarkers for DLBCL diagnosis, subtype classification and outcome prediction. In 2007, Lawrie et al (16) used a microarray analysis on four prototypical cell lines, and reported that the expression of miR-155, miR-221 and miR-21 was increased in DLBCL cells compared with normal peripheral blood B cells; however, there was no difference between DLBCL and FL cells. Another study, using RT-qPCR analysis, demonstrated that four miRs (miR-330, miR-17-5p, miR-106a and miR-210) accurately diagnosed DLBCL and FL cases (15).

A recent significance analysis of microarrays (SAM) identified 55 dysregulated miRs, with a false-identification rate of $<20 \%$, that distinguished DLBCL from lymph nodes (LNs) (17). In addition, the study used a prediction analysis of microarrays to determine the minimum number of miRs that was able to distinguish DLBCLs from LNs, and identified 23 dysregulated miRs that best discriminated the two groups with a prediction accuracy of $96 \%$ (17). A minimum number of $25 \mathrm{miRs}$ 
correctly distinguished the de novo DLBCLs from LNs with an accuracy of $98 \%$, and $32 \mathrm{miRs}$ distinguished transformed DLBCLs from LNs with an accuracy of $93 \%$ (17). This study suggests that miRs have the potential to differentially diagnose DLBCL and inflammatory LNs, including de novo and transformed DLBCL. However, these results require clinical validation in a multi-center, double-blind study with a large sample size prior to being used in the clinical diagnosis and differential diagnosis of DLBCL. A recent study confirmed that miR-18b, miR-19b, miR-20a, miR-92 and miR-106a have an increased expression in GCB-type DLBCL, and have a higher sensitivity and specificity in the diagnosis of GCB-type DLBCL compared with non-GCB-type DLBCL (58).

Fang et al (14) identified that five miRs (miR-15a, miR-16-1, miR-21, miR-29c and miR-155) are significantly elevated in DLBCL serum compared with normal control serum, while miR-34a is downregulated, which suggests that miR expression profiles in serum are a potentially useful tool as a novel non-invasive biomarker for the diagnosis of DLBCL. Baraniskin et al (59) verified that miRs are detectable in the cerebrospinal fluid (CSF) of patients with primary central nervous system lymphoma (PCNSL), using RT-qPCR assays. Furthermore, the authors observed that miR-21, miR-19 and miR-92a were significantly increased in CSF samples from patients with PCNSL compared with control patients that had inflammatory central nervous system (CNS) disease and other neurological disorders. The combined expression analysis of miR-21, miR-19 and miR-92a had a significant diagnostic value for PCNSL due to the high sensitivity and specificity (59). This suggests that miRs detected in the CSF may serve as markers for the diagnosis of PCNSL. Similarly, Robertus et al (60) demonstrated that the expression of miR-17-5p was higher in the CNS compared with testicular and nodal DLBCL. In addition, the authors observed that miR-127 expression was significantly increased in testicular DLBCL compared with CNS and nodal DLBCL, indicating that increased expression levels of miR-127 may be associated with testicular infiltration (60).

Potential biomarkers for subtype classification. Using microarray analysis, Culpin et al (61) identified a nine-miR signature that discriminated between ABC-like and GCB-like DLBCL. However this result requires verification using clinical pathology.

As previously described, Lawrie et al (16) reported that miR-155, miR-221 and miR-21 have an increased expression in patients with ABC-type DLBCL compared with GCB-type. The authors also reported that miR-155 and miR-21 have an increased expression in ABC compared with GCB cells. Similarly, in 2013, Caramuta et al (17) identified a six-miR signature, comprising miR-let-7g, miR-155, miR-29c, miR-146a, miR-451 and miR-16, that discriminated patients with GCB-type from non-GCB using SAM. Furthermore, the authors used RT-qPCR to validate these results, demonstrating that there was a significant overexpression of miR-155 and miR-146a in the non-GCB group (17). These findings demonstrate that miR expression profiles may discriminate between various subtypes and various cell origins in DLBCL. Cao et al (62) demonstrated, using a TaqMan RT-PCR method, that the expression levels of miR-146b-5p in 62 patients with nodal DLBCL was downregulated compared with normal controls; however, the expression of miR-146b-5p was significantly increased in GCB-type DLBCL compared with non-GCB types, suggesting that miR-146b-5p may be a marker for subtype classification. The expression of miR-221 is increased in ABC-type DLBCL compared with GCB-type, and miR-221 has been revealed to inhibit normal erythropoiesis through downregulating the mast/stem cell growth factor receptor c-Kit (63). However, it has been demonstrated that c-Kit is not a significant target of miR-221 (16). Another study identified that cyclin-dependent kinase inhibitor 1B (P27KIP1) is a potential target of miR-221 (64); however, the mechanism and clinical significance of miR-221 and P27KIP1 remains to be investigated. Montes-Moreno et al (55) revealed that there are eight types of miRs that are differentially expressed between various subtypes of DLBCL, including miR-331, miR-151, miR-28 and miR-454-3p, which are all significantly increased in GCB-type DLBCL; and miR-221, miR-451, miR-222 and miR-144, which are all upregulated in ABC-type DLBCL. These results may be useful in the clinical diagnosis of DLBCL subtypes.

DLBCL may be grouped into GCB-type and ABC-type, and may be additionally classified into de novo and transformed DLBCL. Numerous studies are investigating methods to diagnose the subtypes of DLBCL. Caramuta et al (17) performed SAM to directly compare de novo and transformed DLBCL and identified that $10 \mathrm{miRs}$ (miR-29b, miR-155, miR-16, miR-146a, miR-142-5p, let-7i, miR-107, let-7f, miR-34a and miR-103) exhibit increased expression levels, whilst miR-140 exhibits decreased expression levels, in de novo DLBCL compared with transformed DLBCL. Furthermore, the authors revealed that miRs are associated with the disease stage of de novo DLBCL and identified a single miR, miR-494, that is upregulated in stage III-IV de novo DLBCL compared with stage I-II (17).

Potential biomarkers for prognosis. DLBCL is a highly heterogeneous malignant tumor, and the clinical effects and prognoses vary between patients. Stratified and individualized therapy are essential in treating DLBCL; however, how to select the most effective treatment and clinical approach for patients is an issue that remains unresolved. To achieve this goal, the international prognostic index (IPI) and other prognostic evaluation systems were created. However, due to the tumor heterogeneity, patients with similar IPI scores have been shown to exhibit varying prognoses (65); therefore, a more effective prognostic evaluation system is required to provide a basis for the stratified treatment required by DLBCL patients.

In 2007, Lawrie et al (16) reported that an increased expression of miR-21 in DLBCL is associated with an improved prognostic outcome. Subsequently, the authors obtained similar results using RT-qPCR and demonstrated that high levels of miR-21 in the serum of patients with DLBCL are associated with an improved relapse-free survival time (36). Chen et al (66) reported similar results. However, Li et al (37) reported findings contrary to those of the previous studies; the authors demonstrated that there is a high expression of miR-21 in patients with DLBCL, and that the overexpression of miR-21 is associated with the poor prognosis of patients. The discrepancy in the results may 
Table I. miRs that are aberrantly expressed in diffuse large B-cell lymphoma and their target genes.

\begin{tabular}{|c|c|c|}
\hline $\operatorname{miR}$ & Targets & References \\
\hline miR-155 & $\begin{array}{l}\text { MAD1, MXI1, MNT, } \\
\text { MYC, BIC RNA, SMAD5, } \\
\text { HGAL, HDAC4, PIK3RI }\end{array}$ & $(11,21,24,27,29,30)$ \\
\hline miR-21 & $\begin{array}{l}\text { PDCD4, TPM1, PTEN, } \\
\text { PLAG1, E2F3, JAG1, SKI, STAT3 }\end{array}$ & $(10-12,15,32-37)$ \\
\hline miR-17-92 & $\begin{array}{l}\text { c-MYC, gene amplifications (13q31), } \\
\text { BIM, PTEN, E2F1 }\end{array}$ & $(3,16,40-43)$ \\
\hline miR-17, miR-106a, 106b & $\mathrm{P} 21$ & $(45)$ \\
\hline $\operatorname{miR}-150$ & c-MYB & $(46-48)$ \\
\hline miR-15a, miR-16 & BCL-2 & $(49)$ \\
\hline miR-181a & FOXP1, MGMT & $(50)$ \\
\hline miR-9 & Blimp-1 & $(51)$ \\
\hline miR-199 & IKK- $\beta$ & $(52)$ \\
\hline miR-221 & c-Kit, P27KIP1 & $(64,65)$ \\
\hline $\operatorname{miR}-127$ & BCL-6 & $(71)$ \\
\hline
\end{tabular}

miR, microRNA; MAD1, mitotic arrest deficient-like 1; MXI1, MYC-associated factor X-interacting protein 1; MNT, MYC-associated factor X network transcriptional repressor; MYC, V-Myc avian myelocytomatosis viral oncogene homolog; BIC, B-cell integration cluster; HGAL, human germinal center-associated lymphoma; HDAC4, histone deacetylase 4; PIK3RI, phosphatidylinositol 3-kinase regulatory subunit; PDC4, programmed cell death 4 (neoplastic transformation inhibitor); TPM1, tropomyosin 1- $\alpha$; PTEN, phosphatase and tensin homolog; PLAG1, pleomorphic adenoma gene 1; E2F3, E2F transcription factor 3; JAG1, Jagged 1; SKI, avian sarcoma viral proto-oncogen; STAT3, signal transducer and activator of transcription 3; BCL, B-cell lymphoma; BIM, BCL-2 interacting mediator of cell death; E2F1, E2F transcription factor 1; P21, cyclin-dependent kinase inhibitor 1; MYB, V-Myb avian myeloblastosis viral oncogene homolog; FOXP1, forkhead box protein P1; MGMT, O-6-methylguanine-DNA methyltransferase; Blimp-1, B lymphocyte-induced maturation protein-1; IKK- $\beta$, inhibitor of nuclear factor kappa-B kinase subunit $\beta$; P27KIP1, cyclin-dependent kinase inhibitor 1B.

be due to the methods used to identify miRs in the early stages of disease and requires additional study. Additionally, Roehle et al (15) observed that patients with downregulated expression levels of miR-21, miR-23a, miR-27a and miR-34a had a poor overall survival (OS) time, whilst those with low expression levels of miR-19a had a shorter event-free survival (EFS) time and low expression levels of miR-195 and miR-let7g have a longer EFS time. These results reveal that these miRs have prognostic abilities in patients with DLBCL. Numerous studies have identified that miRs are stable and reproducible in serum, and may be detected directly from serum $(5,67-69)$. miRs are shorter than mRNAs, and are less vulnerable to degradation by ribonucleases and, unlike proteins, are easier to detect (5). In addition to serum, evidence is emerging that tumor-derived miRs are present and detectable in other human bodily fluids, including plasma and urine (5). Consequently, miRs appear to be potentially the most accessible and non-invasive biomarkers for the diagnosis of DLBCL. An additional study has observed that miR-18a, miR-181a and miR-222 may predict OS and progression-free survival (PFS) times in DLBCL patients treated with R-CHOP (6).

Previously, Caramuta et al (17) identified that there is a direct association between increased expression of DiGeorge syndrome chromosomal region 8 (DGCR8) and a high IPI score in patients with DLBCL. In addition, patients with a high TAR (HIV-1) RNA binding protein 2 (TARBP2) and Drosha ribonuclease type III (DROSHA) expression respond more poorly to chemotherapy treatment, which suggests that these genes may be potential predictors of the chemotherapy response in de novo DLBCL. DGCR8, TARBP2 and DROSHA are closely associated with the expression of miRs in DLBCL, which indicates that the alterations and differences in the expression levels of miRs in patients with DLBCL may be used for predicting the efficacy of R-CHOP-treated patients. Ohyashiki et al (70) reported that, in the plasma of patients with NHL, the expression of miR-92a may be used as a novel biomarker for diagnosing and monitoring lymphoma patients following chemotherapy. Notably, low levels of plasma miR-92a in the complete remission phase of NHL are associated with a significantly high relapse rate (RR), which suggests that plasma miR-92a levels may be used to monitor patients with NHL (70). This may also apply to patients with DLBCL.

Song et al (71) used RT-qPCR to determine the treatment response-associated serum miR profiles, and demonstrated that, in patients with DLBCL, there were various serum expression levels of miRs, which may be used to evaluate the efficacy of R-CHOP treatment. The authors demonstrated that a serum signature of five miRs, comprising miR-224, miR-455-3p, miR-1236, miR-33a and miR-520d-3p, was significantly associated with RR, OS and EFS times of patients with DLBCL following R-CHOP treatment. This five-miR signature is a significant predictor of the response of a patient to R-CHOP treatment, which is independent from the IPI score. However, this signature requires a multi-center, large sample size verification. 
Low expression levels of miR-127 have been associated with poor OS and EFS times in patients with DLBCL (15). In 2006, Saito et al (72) reported that miR-127 and BCL-6 exhibited opposite patterns of expression in DLBCL; therefore revealing that miR-127 may be directly or indirectly suppressed by BCL-6 in DLBCL. BCL-6, a known proto-oncogene, encodes a transcriptional repressor and is expressed in GCB-originated NHL (2). However, a high expression level of BCL-6 is associated with a good prognosis in patients with DLBCL, which is independent of IPI score. miR-127, as a tumor suppressor, may act as a prognostic indicator for DLBCL; however, this hypothesis requires additional clarification.

In conclusion, the expression of a specific miR signature and miR machinery are associated with the diagnosis, subtype classification and prognosis of DLBCL, including OS and PFS times and response to R-CHOP treatment. The miRs identified in DLBCL and their functions are presented in Table II.

Although the expression profile of miRs has been validated as a critical tool for DLBCL diagnosis, classification and prognosis, numerous problems remain: There is not a uniform cut-off value for detected miRs; there is no standard test method; and dysregulated miRs may be detected in more than one cancer.

\section{5. miRs as potential therapeutic targets in DLBCL}

DLBCL is an aggressive disease with considerable biological and clinical heterogeneity. Despite recent therapeutic advances, $\leq 50 \%$ of patients relapse following standard chemoimmunotherapy with the CHOP regimen (73). Overcoming primary drug resistance in patients and improving the efficacy of the drugs is challenging. However, biological therapies, including miR-based therapies, are emerging as novel strategies for the treatment and potential cure of DLBCL. In the past several years, there has been major interest in miRs as therapeutic targets for cancer, and a number of promising findings have been reported. For example, miR-199a may be a potential therapeutic target for cervical cancer therapy; anti-miR-199a has been demonstrated to reduce the expression of miR-199a and decrease cell growth, and also acts synergistically with cisplatin to inhibit cell growth (74). Therefore, the concept of miRs as treatment tools may be extrapolated to other miRs and diseases.

As miRs may be divided into tumor suppressor miRs and oncomiRs, certain researchers have hypothesized that miR-based therapies may involve two different approaches: Use of anti-oncomiRs to reduce oncogenic miR expression, or restoration of tumor suppressor miRs (3). Sandhu et al (3) reported that synthetic anti-miR oligonucleotides (AMOs), which have 2-O-methyl modification, effectively inhibit miRs in cell culture and xenograft mouse models, but only work at high doses $(3,75)$. An alternative to AMOs is locked nucleic acid (LNA)-based anti-miRs, which have been demonstrated to be more stable and less toxic in inhibiting endogenous miRs in vivo compared with AMOs $(3,76,77)$. Another strategy, termed miR-sponge, may inhibit or delete miRs individually (78). With regard to restoring tumor suppressor miRs, the use of synthetic miR mimics, including miR-29 mimics in acute myelogenous leukemia cell lines, was demonstrated to induce apoptosis of cells (79), whilst adenovirus-associated vectors have been demonstrated to increase the expression of tumor suppressor miRs (3).

Bouchie (8) designed the miR-34a-mimic for the treatment of primary liver cancer, based on miR-34a expression and functional characteristics in primary liver cancer. In 2013, the first drug, MRX34, to target miR-34a entered clinical trials. If the results from phase I are encouraging, it may provide a basis for the development of other miR drugs for use in other types of cancer.

Bai et al (80) observed that knockdown of miR-21 using antisense oligonucleotides significantly increased the cytotoxic effects of the CHOP treatment regimen in CRL2631 human peripheral blood DLBCL cells. In addition, the authors used a luciferase reporter assay and demonstrated that the antisense oligonucleotides repressed the activity of the PI3K/AKT signaling pathway through the regulation of PTEN. This result demonstrates that use of miR antisense oligonucleotide therapy to treat DLBCL is effective. Gu et al (81) demonstrated that the inhibition of miR-21 using transfection with anti-miR-21 induces the suppression of cell proliferation and invasion, as well as increasing the apoptosis of DLBCL cells in vitro. This provides clear evidence that miR-21 is a biological treatment for DLBCL.

Another potential target for the treatment of DLBCL is protein kinase $\mathrm{C}(\mathrm{PKC})$, which modulates downstream signaling via the NF- $\kappa \beta$ survival pathway in B cells (82). A PKC inhibitor, enzastaurin, has been trialled in relapsed or refractory DLBCL, and the results are encouraging (82). Therefore, it may be hypothesized that it is possible to treat DLBCL using miRs in the regulation of NF- $\kappa \beta$ and the adjustment of the PKC signaling pathway.

miR-17-92 works in combination with the c-MYC oncogene to reduce the degree of apoptosis of lymphoma cells (39). Overexpression of miR-17-92 activates the PI3K/AKT pathway and inhibits chemotherapy-induced apoptosis in mantle cell lymphoma cell lines (83). In 2013, Caramuta et al (17) demonstrated that in OCI-Ly-1 and OCI-Ly-3 human DLBCL cell lines an inhibition of TARBP2 expression significantly decreased the viability and increased the apoptosis of the cells. Additionally, overexpression of activating transcription factor (ATF) 3, ATF4, ATF5, c-Jun, JunD and caspase 3 are associated with sensitivity to bortezomib-induced apoptosis of cells (84). These results demonstrate that an inhibition in the expression of miR-17-92 and TARBP2, which induces the expression of ATF3, ATF4, ATF5, c-Jun, JunD and caspase 3, may be important therapeutic targets for DLBCL.

However, challenges remain in using miRs as therapeutic targets for the clinical treatment of DLBCL. First, the role of miRs as oncogenes or tumor suppressor genes remains unclear, since a single miR may regulate the expression of almost 200 genes. Therefore, a clear understanding of the roles of these genes is required to quantify the effect of miR inhibition or overexpression. Second, miRs as therapeutic targets for DLBCL require a strict assessment with regard to their use in biological therapy. The effect on the immune response, toxicity of biological drugs and unknown side effects remain unknown. Third, tissue specificity of miRs may have to be overcome. To render miRs as biological drugs that are safe and 


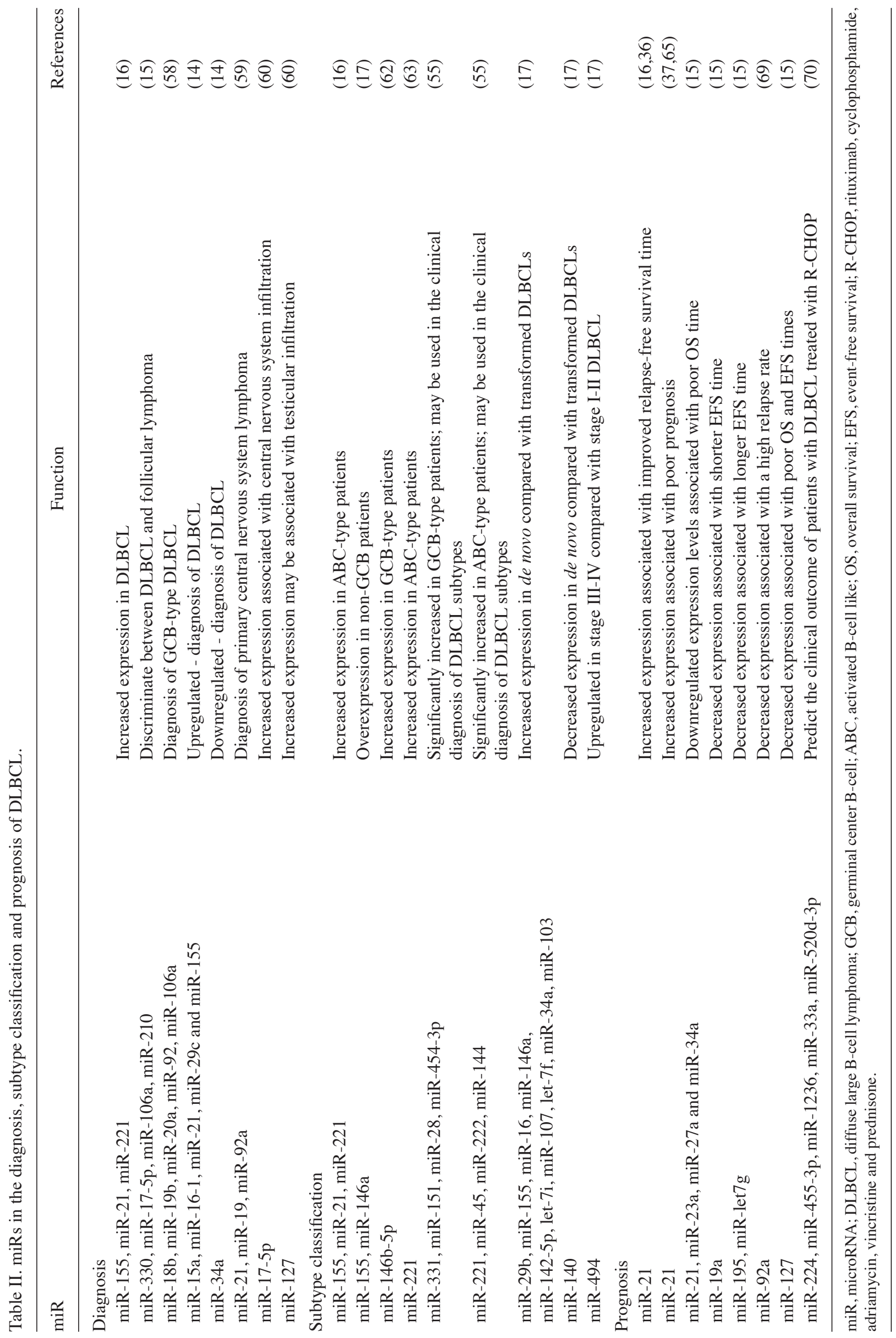


effectively reach the target tissue are challenges that require resolution prior to clinical use. The aforementioned problems have been investigated by a few studies $(85,86)$. Due to the advancement of biological targeted therapy technology, in the near future, miRs may be biological treatments, which may be the preferred treatment for patients with DLBCL, particularly refractory and relapse patients.

\section{Conclusion}

DLBCL is a disease that often relapses and is refractory to various therapies (82). The diagnosis, prognosis and treatment of DLBCL have improved in the past decade; however, additional study is required. The identification of miRs has created a novel opportunity to increase the understanding in the diagnosis, prognosis and treatment methods for these patients.

There has been great success concerning the role of miRs in DLBCL. The dysregulation of miRs in this cancer suggest that miRs are important in the development of DLBCL (7). The expression levels of miRs in various cells, tissues, organs, tumors and stages of DLBCL vary, which demonstrates that miR expression is tissue-specific, and the miR profile in a tissue may be used to diagnose, classify and prognose DLBCL. In the future, miRs may become targeted therapies for DLBCL. Since miRs are critical to DLBCL, there have been numerous studies concerning the mechanisms and functions of the dysregulated miRs detected in cancer tissues $(14,87)$.

However, although there is evidence to suggest that miRs may be useful in clinical settings, additional investigation is required and numerous issues remain. A single blood-based biomarker lacks sufficient sensitivity, specificity and accuracy for clinical use (68). Therefore, it may be hypothesized that a combination of several miRs is likely to be more effective compared with a single miR. This hypothesis is validated by a previous study that demonstrated that a cluster of biomarkers for one disease would be an improved diagnostic tool with a much higher sensitivity, specificity and accuracy (68). Therefore, studies that provide beneficial information concerning miRs may aid in overcoming the adverse effects and defects, which may enable the use of miRs in the pathogenesis, diagnosis, prognosis and as therapeutic targets of DLBCL.

In summary, miRs are potential biomarkers for the diagnosis, classification and prognosis of DLBCL, and may be potential targets for gene therapy in this disease.

\section{References}

1. Lossos IS and Morgensztern D: Prognostic biomarkers in diffuse large B-Cell lymphoma. J Clin Oncol 24: 995-1007, 2006.

2. Westin JR and Fayad LE: Beyond R-CHOP and the IPI in large-cell lymphoma: Molecular markers as an opportunity for stratification. Curr Hematol Malig Rep 4: 218-224, 2009.

3. Sandhu SK, Croce CM and Garzon R: Micro-RNA expression and function in lymphomas. Adv Hematol 2011: 1-12, 2011.

4. Wang W and Luo YP: MicroRNAs in breast cancer: Oncogene and tumor suppressors with clinical potential. J Zhejiang Univ Sci B 16: 18-31, 2015.

5. Catuogno S, Esposito CL, Quintavalle C, Cerchia L, Condorelli G and De Franciscis V: Recent advance in biosensors for microRNAs detection incancer. Cancers (Basel) 3: 1877-1898, 2011.
6. Di Lisio L, Martinez N, Montes-Moreno S, Piris-Villaespesa M, Sanchez-Beato $M$ and Piris MA: The role of miRNAs in the pathogenesis and diagnosis of B-cell lymphomas. Blood 120: 1782-1790, 2012.

7. Yu DC, Li QG, Ding XW and Ding YT: Circulating microRNAs: Potential biomarkers for cancer. Int J Mol Sci 12: 2055-2063, 2011.

8. Bouchie A: First microRNA mimic enters clinic. Nat Biotechnol 31: 577, 2013.

9. Lawrie CH: MicroRNAs and lymphomagenesis: A functional review. Br J Haematol 160: 571-581, 2013.

10. Löffler D, Brocke-Heidrich K, Pfeifer G, Stocsits C, Hackermüller J, Kretzschmar AK, Burger R, Gramatzki M, Blumert C, Bauer K, et al: Interleukin-6 dependent survival of multiple myeloma cells involves the Stat3-mediated induction of microRNA-21 through a highly conserved enhancer. Blood 110: 1330-1333, 2007.

11. Meng F, Henson R, Wehbe-Janek H, Ghoshal K, Jacob ST and Patel T: MicroRNA-21 regulates expression of the PTEN tumor suppressor gene in human hepatocellular cancer. Gastroenterology 133: 647-658, 2007.

12. Frankel LB, Christoffersen NR, Jacobsen A, Lindow M, Krogh A and Lund AH: Programmed cell death 4 (PDCD4) is an important functional target of the microRNA miR-21 in breast cancer cells. J Biol Chem 283: 1026-1033, 2008.

13. Chen C, Ridzon DA, Broomer AJ, Zhou Z, Lee DH, Nguyen JT, Barbisin M, Xu NL, Mahuvakar VR, Andersen MR, et al: Real-time quantification of microRNAs by stem-loop RT-PCR. Nucleic Acids Res 33: e179, 2005.

14. Fang C, Zhu DX, Dong HJ, Zhou ZJ, Wang YH, Liu L, Fan L, Miao KR, Liu P, Xu W and Li JY: Serum microRNAs are promising novel biomarkers for diffuse large B cell lymphoma. Ann Hematol 91: 553-559, 2012.

15. Roehle A, Hoefig KP, Repsilber D, Thorns C, Ziepert M, Wesche KO, Thiere M, Loeffler M, Klapper W, Pfreundschuh M, et al: MicroRNA signatures characterize diffuse large B-cell lymphomas and follicular lymphomas. Br J Haematol 142: 732-744, 2008.

16. Lawrie CH, Soneji S, Marafioti T, Cooper CD, Palazzo S, Paterson JC, Cattan H, Enver T, Mager R, Boultwood J, et al: Microrna expression distinguishes between germinal center $B$ cell-like and activated B cell-like subtypes of diffuse large B cell lymphoma. Int J Cancer 121: 1156-1161, 2007.

17. Caramuta S, Lee L, Ozata DM, Akçakaya P, Georgii-Hemming P, Xie H, Amini RM, Lawrie CH, Enblad G, Larsson C, et al: Role of microRNAs and microRNA machinery in the pathogenesis of diffuse large B-cell lymphoma. Blood Cancer J 3: e152, 2013.

18. Di Lisio L, Sánchez-Beato M, Gómez-López G, Rodríguez ME, Montes-Moreno S, Mollejo M, Menárguez J, Martínez MA, Alves FJ, Pisano DG, et al: MicroRNA signatures in B-cell lymphomas. Blood Cancer J 2: e57, 2012.

19. Li C, Kim SW, Rai D, Bolla AR, Adhvaryu S, Kinney MC, Robetorye RS and Aguiar RC: Copy number abnormalities, MYC activity and the genetic fingerprint of normal B cells mechanistically define the microRNA profile of diffuse large B-cell lymphoma. Blood 113: 6681-6690, 2009.

20. Zhong H, Xu L, Zhong JH, Xiao F, Liu Q, Huang HH and Chen FY: Clinical and prognostic significance of miR-155 and miR-146a expression levels in formalin-fixed/paraffin-embedded tissue of patients with diffuse B-cell lymphoma. Exp Ther Med 3: 763-770, 2012.

21. Metzler M, Wilda M, Busch K, Viehmann S and Borkhardt A: High expression of precursor microRNA-155/BIC RNA in children with Burkitt lymphoma. Genes Chromosomes Cancer 39: 167-169, 2004.

22. Linnstaedt SD, Gottwein E, Skalsky RL, Luftig MA and Cullen BR: Virally induced cellular MicroRNA miR-155 plays a key role in B-Cell immortalization by Epstein-Barr virus. J Virol 84: 11670-11678, 2010.

23. Lu F, Weidmer A, Liu CG, Volinia S, Croce CM and Lieberman PM: Epstein-Barr virus-induced miR-155 attenuates NF-kappaB signaling and stabilizes latent virus persistence. J Virol 82: 10436-10443, 2008.

24. Rai D, Kim SW, McKeller MR, Dahia PL and Aguiar RC: Targeting of SMAD5 links microRNA-155 to the TGF-beta pathway and lymphomagenesis. Proc Natl Acad Sci USA 107: 3111-3116, 2010.

25. Yin Q, McBride J, Fewell C, Lacey M, Wang X, Lin Z, Cameron J and Flemington EK: MicroRNA-155 is an Epstein-Barr Virus induced gene that modulates Epstein Barr virus regulated gene expression pathways. J Virol 82: 5295-5306, 2008. 
26. BolisettyMT,DyG,Tam WandBeemon KL:Reticuloendotheliosis virus strain $\mathrm{T}$ induces miR-155, which targets JARID2 and promotes cell survival. J Virol 83: 12009-12017, 2009.

27. Eis PS, Tam W, Sun L, Chadburn A, Li Z, Gomez MF, Lund E and Dahlberg JE: Accumulation of miR-155 and BIC RNA in human B cell lymphomas. Proc Natl Acad Sci USA 102: 3627-3632, 2005.

28. Rai D, Karanti S, Jung I, Dahia PL and Aguiar RC: Coordinated expression of microRNA-155 and predicted target genes in diffuse large B-cell lymphoma. Cancer Genet Cytogenet 181: $8-15,2008$.

29. Martín-Pérez D, Vargiu P, Montes-Moreno S, León EA, Rodríguez-Pinilla SM, Lisio LD, Martínez N, Rodríguez R, Mollejo M, Castellvi J, et al: Epstein-Barr virus microRNAs repress BCL6 expression in diffuse large B-cell lymphoma. Leukemia 26: 180-183, 2012.

30. Huang X, Shen Y, Liu M, Bi C, Jiang C, Iqbal J, McKeithan TW, Chan WC, Ding SJ and Fu K: Quantitative proteomics reveals that miR-155 regulates the PI3K-AKT pathway in diffuse large B-cell lymphoma. Am J Pathol 181: 26-33, 2012.

31. Pan X, Wang ZX and Wang R: MicroRNA-21: A novel therapeutic target in human cancer. Cancer Biol Ther 10: 1224-1232, 2010.

32. Si ML, Zhu S, Wu H, Lu Z, Wu F and Mo YY: MiR-21-mediated tumor growth. Oncogene 26: 2799-2803, 2007.

33. Chan JA, Krichevsky AM and Kosik KS: MicroRNA-21 is an antiapoptotic factor in human glioblastoma cells. Cancer Res 65 6029-6033, 2005.

34. Cheng AM, Byrom MW, Shelton J and Ford LP: Antisense inhibition of human miRNAs and indications for an involvement of miRNA in cell growth and apoptosis. Nucleic Acids Res 33: 1290-1297, 2005.

35. Zhu S, Si ML, Wu H and Mo YY: MicroRNA-21 targets the tumor suppressor gene tropomyosin 1 (TPM1). J Biol Chem 282: 14328-14336, 2007.

36. Lawrie CH, Gal S, Dunlop HM, Pushkaran B, Liggins AP, Pulford K, Banham AH, Pezzella F, Boultwood J, Wainscoat JS, et al: Detection of elevated levels of tumour-associated microRNAs in serum of patients with diffuse large B-cell lymphoma. Br J Haematol 141: 672-675, 2008.

37. Li CH, Fu R, Wang YH, Song WJ, Ruan EB, Qu W, Wang HQ, Wang GJ, Song J, Wang XM, et al: Expression and clinical significance of miR-21 in diffuse large B cell lymphoma. Zhongguo Shi Yan Xue Ye Xue Za Zhi 22: 339-343, 2014 (In Chinese).

38. O'Donnell KA, Wentzel EA, Zeller KI, Dang CV and Mendell JT: c-Myc regulated microR NAs modulate E2F1 expression. Nature 435: 839-843, 2005.

39. He L, Thomson JM, Hemann MT, Hernando-Monge E, Mu D, Goodson S, Powers S, Cordon-Cardo C, Lowe SW, Hannon GJ and Hammond SM: A microRNA polycistron as a potential human oncogene. Nature 435: 828-833, 2005

40. Lawrie CH, Chi J, Taylor S, Tramonti D, Ballabio E, Palazzo S, Saunders NJ, Pezzella F, Boultwood J, Wainscoat JS and Hatton CS: Expression of microRNAs in diffuse large B cell lymphoma is associated with immunophenotype, survival and transformation from follicular lymphoma. J Cell Mol Med 13: 1248-1260, 2009.

41. Ventura A, Young AG, Winslow MM, Lintault L, Meissner A, Erkeland SJ, Newman J, Bronson RT, Crowley D, Stone JR, et al: Targeted deletion reveals essential and overlapping functions of the miR-17 through 92 family of miRNA clusters. Cell 132: $875-886,2008$

42. Chen W, Houldsworth J, Olshen AB, Nanjangud G, Chaganti S, Venkatraman ES, Halaas J, Teruya-Feldstein J, Zelenetz AD and Chaganti RS: Array comparative genomic hybridization reveals genomic copy number changes associated with outcome in diffuse large B-cell lymphomas. Blood 107: 2477-2485, 2006

43. Tam W: Micro-classifying diffuse large B-cell lymphomas Blood 113: 6506-6507, 2009

44. Hayashita Y, Osada H, Tatematsu Y, Yamada H, Yanagisawa K, Tomida S, Yatabe Y, Kawahara K, Sekido Y and Takahashi T: A polycistronic microRNA cluster, miR-17-92, is overexpressed in human lung cancers and enhances cell proliferation. Cancer Res 65: 9628-9632, 2005

45. Thapa DR, Li X, Jamieson BD and Martínez-Maza O Overexpression of microRNAs from the miR-17-92 paralog clusters in AIDS-related non-Hodgkin's lymphomas. PLoS One 6: e20781, 2011.

46. Xiao C, Calado DP, Galler G, Thai TH, Patterson HC, Wang J, Rajewsky N, Bender TP and Rajewsky K: MiR-150 controls B cell differentiation by targeting the transcription factor c-Myb. Cell 131: 146-159, 2007.
47. Tan LP, Wang M, Robertus JL, Schakel RN, Gibcus JH, Diepstra A, Harms G, Peh SC, Reijmers RM, Pals ST, et al: MiRNA profiling of B-cell subsets: Specific miRNA profile for germinal center B cells with variation between centroblasts and centrocytes. Lab Invest 89: 708-716, 2009.

48. Tober J, McGrath KE and Palis J: Primitive erythropoiesis and megakaryopoiesis in the yolk sac are independent of c-myb. Blood 111: 2636-2639, 2008.

49. Calin GA, Cimmino A, Fabbri M, Ferracin M, Wojcik SE, Shimizu M, Taccioli C, Zanesi N, Garzon R, Aqeilan RI, et al: MiR-15a and miR-16-1 cluster functions in human leukemia. Proc Natl Acad Sci USA 105: 5166-5171, 2008.

50. Alencar AJ, Malumbres R, Kozloski GA, Advani R, Talreja N, Chinichian S, Briones J, Natkunam Y, Sehn LH, Gascoyne RD, et al: MicroRNAs are independent predictors of outcome in diffuse large B-cell lymphoma patients treated with R-CHOP. Clin Cancer Res 17: 4125-4135, 2011.

51. Pasqualucci L, Compagno M, Houldsworth J, Monti S, Grunn A, Nandula SV, Aster JC, Murty VV, Shipp MA and Dalla-Favera R: Inactivation of the PRDM1/BLIMP1 gene in diffuse large B cell lymphoma. J Exp Med 203: 311-317, 2006.

52. Chen R, Alvero AB, Silasi DA, Kelly MG, Fest S, Visintin I, Leiser A, Schwartz PE, Rutherford T and Mor G: Regulation of IKKbeta by miR-199a affects NF-kappaB activity in ovarian cancer cells. Oncogene 27: 4712-4723, 2008.

53. Al-Katib A, Arnold AA, Aboukameel A, Sosin A, Smith P, Mohamed AN, Beck FW and Mohammad RM: I-kappa-kinase-2 (IKK-2) inhibition potentiates vincristine cytotoxicity in non-Hodgkin's lymphoma. Mol Cancer 9: 228,2010

54. Jima DD, Zhang J, Jacobs C, Richards KL, Dunphy CH, Choi WW, Au WY, Srivastava G, Czader MB, Rizzieri DA, et al: Deep sequencing of the small RNA transcriptome of normal and malignant human B cells identifies hundreds of novel microRNAs. Blood 116: e118-e127, 2010.

55. Montes-Moreno S, Martinez N, Sanchez-Espiridión B, Díaz Uriarte R, Rodriguez ME, Saez A, Montalbán C, Gomez G, Pisano DG, García JF, et al: MiRNA expression in diffuse large B-cell lymphoma treated with chemoimmunotherapy. Blood 118: 1034-1040, 2011

56. López AN and Pous LH: MicroRNAs in lymphoma. In: MicroRNAs in Cancer Translational Research. Cho WCS (ed). Springer, Netherlands, Heidelberg, pp239-267, 2011.

57. Shen J, Liu Z, Todd NW, Zhang H, Liao J, Yu L, Guarnera MA, Li R, Cai L, Zhan M and Jiang F: Diagnosis of lung cancer in individuals with solitary pulmonary nodules by plasma microRNA biomarkers. BMC Cancer 11: 374, 2011.

58. Fassina A, Marino F, Siri M, Zambello R, Ventura L, Fassan M, Simonato $\mathrm{F}$ and Cappellesso R: The miR-17-92 microRNA cluster: A novel diagnostic tool in large B-cell malignancies. Lab Invest 92: 1574-1582, 2012.

59. Baraniskin A, Kuhnhenn J, Schlegel U, Chan A, Deckert M, Gold R, Maghnouj A, Zöllner H, Reinacher-Schick A, Schmiegel W, et al: Identification of microRNAs in the cerebrospinal fluid as marker for primary diffuse large B-cell lymphoma of the central nervous system. Blood 117: 3140-3146, 2011.

60. Robertus JL, Harms G, Blokzijl T, Booman M, de Jong D, van Imhoff $\mathrm{G}$, Rosati S, Schuuring $\mathrm{E}$, Kluin $\mathrm{P}$ and van den Berg A: Specific expression of miR-17-5p and miR-127 in testicular and central nervous system diffuse large B-cell lymphoma. Mod Pathol 22: 547-555, 2009.

61. Culpin RE, Proctor SJ, Angus B, Crosier S, Anderson JJ and Mainou-Fowler T: A 9 series microRNA signature differentiates between germinal centre and activated B-cell-like diffuse large B-cell lymphoma cell lines. Int J Oncol 37: 367-376, 2010.

62. Cao QW, Li HY, Yao XX and Wang JF: Significance of microRNA-146b-5p in diffuse large B-cell lymphoma and its relationship with risk assessment. Zhonghua Xue Ye Xue Za Zhi 33: 1010-1014, 2012 (In Chinese).

63. Felli N, Fontana L, Pelosi E, Botta R, Bonci D, Facchiano F, Liuzzi F, Lulli V, Morsilli O, Santoro S, et al: MicroRNAs 221 and 222 inhibit normal erythropoiesis and erythroleukemic cell growth via kit receptor down-modulation. Proc Natl Acad Sci USA 102: 18081-18086, 2005.

64. Le Sage C, Nagel R, Egan DA, Schrier M, Mesman E, Mangiola A, Anile C, Maira G, Mercatelli N, Ciafrè SA, et al: Regulation of the p27(Kip1) tumor suppressor by miR-221 and miR-222 promotes cancer cell proliferation. EMBO J 26: 3699-3708, 2007. 
65. Bishton MJ, Hughes S, Richardson F, James E, Bessell E, Sovani V, Ganatra R, Haynes AP, McMillan AK and Fox CP: Delineating outcomes of patients with diffuse large B cell lymphoma using the National Comprehensive Cancer Network-International Prognostic Index and Positron Emission Tomography-defined Remission Status; A population-based analysis. Br J Haematol: Nov 18, 2015 (Epub ahead of print).

66. Chen W, Wang H, Chen H, Liu S, Lu H, Kong D, Huang X, Kong Q and $\mathrm{Lu} \mathrm{Z:} \mathrm{Clinical} \mathrm{significance} \mathrm{and} \mathrm{detection} \mathrm{of} \mathrm{microRNA-21} \mathrm{in}$ serum of patients with diffuse large B-cell lymphoma in Chinese population. Eur J Haematol 92: 407-412, 2014.

67. Chen X, Ba Y, Ma L, Cai X, Yin Y, Wang K, Guo J, Zhang Y, Chen J, Guo X, et al: Characterization of microRNAs in serum: A novel class of biomarkers for diagnosis of cancer and other diseases. Cell Res 18: 997-1006, 2008.

68. Mitchell PS, Parkin RK, Kroh EM, Fritz BR, Wyman SK, Pogosova-Agadjanyan EL, Peterson A, Noteboom J, O'Briant KC Allen A, et al: Circulating microRNAs as stable blood-based markers for cancer detection. Proc Natl Acad Sci USA 105 10513-10518, 2008

69. Gilad S, Meiri E, Yogev Y, Benjamin S, Lebanony D, Yerushalmi N, Benjamin H, Kushnir M, Cholakh H, Melamed N, et al: Serum microRNAs are promising novel biomarkers. PloS One 3: e3148, 2008.

70. Ohyashiki K, Umezu T, Yoshizawa S, Ito Y, Ohyashiki M, Kawashima H, Tanaka M, Kuroda M and Ohyashiki JH: Clinical impact of down-regulated plasma miR-92a levels in non-Hodgkin's lymphoma. Plos One 6: e16408, 2011.

71. Song G, Gu L, Li J, Tang Z, Liu H, Chen B, Sun X, He B, Pan Y, Wang $S$ and Cho WC: Serum microRNA expression profiling predict response to $\mathrm{R}-\mathrm{CHOP}$ treatment in diffuse large $\mathrm{B}$ cell lymphoma patients. Ann Hematol 93: 1735-1743, 2014.

72. Saito Y, Liang G, Egger G, Friedman JM, Chuang JC, Coetzee GA and Jones PA: Specific activation of microRNA-127 with downregulation of the proto-oncogene BCL6 by chromatin-modifying drugs in human cancer cells. Cancer Cell 9: 435-443, 2006.

73. Seshadri T, Kuruvilla J, Crump M and Keating A: Salvage therapy for relapsed/refractory diffuse large B cell lymphoma. Biol Blood Marrow Transplant 14: 259-267, 2008.

74. Lee JW, Choi CH, Choi JJ, Park YA, Kim SJ, Hwang SY, Kim WY, Kim TJ, Lee JH, Kim BG and Bae DS: Altered MicroRNA Expression in Cervical Carcinomas. Clin Cancer Res 14 2535-2542, 2008

75. Trang P, Medina PP, Wiggins JF, Ruffino L, Kelnar K, Omotola M, Homer R, Brown D, Bader AG, Weidhaas JB and Slack FJ: Regression of murine lung tumors by the let-7 microRNA. Oncogene 29: 1580-1587, 2010
76. Vester B and Wengel J: LNA (Locked nucleic acid): Highaffinity targeting of complementary RNA and DNA. Biochemistry 43: 13233-13241, 2004.

77. Elmén J, Lindow M, Schütz S, Lawrence M, Petri A, Obad S, Lindholm M, Hedtjärn M, Hansen HF, Berger U, et al: LNA-mediated microRNA silencing in non-human primates. Nature 452: 896-899, 2008.

78. Hammond SM: Soaking up small RNAs. Nat Methods 4: 694-695, 2007.

79. Bonci D, Coppola V, Musumeci M, Addario A, Giuffrida R, Memeo L, D'Urso L, Pagliuca A, Biffoni M, Labbaye C, et al: The miR-15a-miR-16-1 cluster controls prostate cancer by targeting multiple oncogenic activities. Nat Med 14: 1271-1277, 2008

80. Bai H, Wei J, Deng C, Yang X, Wang C and Xu R: MicroRNA-21 regulates the sensitivity of diffuse large B-cell lymphoma cells to the CHOP chemotherapy regimen. Int J Hematol 97: 223-231, 2013

81. Gu L, Song G, Chen L, Nie Z, He B, Pan Y, Xu Y, Li R, Gao T, Cho WC and Wang S: Inhibition of miR-21 induces biological and behavioral alterations in diffuse large B-cell lymphoma. Acta Haematol 130: 87-94, 2013.

82. Sud R and Friedberg JW: Salvage therapy for relapsed or refractory diffuse large B-cell lymphoma: Impact of prior rituximab. Haematologica 93: 1776-1780, 2008.

83. Rao E, Jiang C, Ji M, Huang X, Iqbal J, Lenz G, Wright G, Staudt LM, Zhao Y, McKeithan TW, et al: The miRNA-17 92 cluster mediates chemoresistance and enhances tumor growth in mantle cell lymphoma via PI3K/AKT pathway activation. Leukemia 26: 1064-1072, 2012.

84. Shringarpure R, Catley L, Bhole D, Burger R, Podar K, Tai YT, Kessler B, Galardy P, Ploegh H, Tassone P, et al: Gene expression analysis of B-lymphoma cells resistant and sensitive to bortezomib. Br J Haematol 134: 145-156, 2006.

85. Ling H, Fabbri $M$ and Calin GA: MicroRNAs and other non-coding RNAs as targets for anticancer drug development. Nat Rev Drug Discov 12: 847-865, 2013.

86. Janssen HL, Reesink HW, Lawitz EJ, Zeuzem S, Rodriguez-Torres M, Patel K, van der Meer AJ, Patick AK, Chen A, Zhou Y, et al: Treatment of HCV infection by targeting microRNA. N Engl J Med 368: 1685-1694, 2013.

87. Berglund M, Thunberg U, Amini RM, Book M, Roos G, Erlanson M, Linderoth J, Dictor M, Jerkeman $M$, Cavallin-Ståhl E, et al: Evaluation of immunophenotype in diffuse large B-cell lymphoma and its impact on prognosis. Mod Pathol 18, 1113-1120, 2005. 